\title{
Chamanes y danzantes en las comunidades originarias del Caribe Sur de Nicaragua
}

\section{Shamans and dancers in the original communities of the South Caribbean of Nicaragua.}

\author{
Leonardo Daniel Lechado Ríos ${ }^{1}$ \\ Universidad Nacional Autónoma de Nicaragua (UNAN)
}

\section{RESUMEN}

Esta investigación es sobre el sitio arqueológico Sombrero Negro en la Región Autónoma de la Costa Caribe Sur (RACCS) de Nicaragua. Este sitio se caracteriza por la presencia de petroglifos, concentraciones de materiales arqueológicos prehispánicos (lítica y cerámica) en superficie y un área de sepulcros. En el lugar fueron encontradas representaciones antropomorfas (chamanes), zoomorfas, fitomorfas, geométricas y abstractas; también, el aprovechamiento de formas en rocas para su estilización. El sitio en cuestión funcionó como un espacio destinado al desarrollo de prácticas ceremoniales y fue ocupado tentativamente entre el 400 a.C. y 440 d.C.

Palabras claves: arqueología; etnografía; petroglifos; ajuar funerario; Nicaragua-Costa caribe

\begin{abstract}
This research is about the Sombrero Negro, archaeological site in the Autonomous Region of the South Caribbean Coast (RACCS) of Nicaragua. This site is characterized by the presence of petroglyphs, concentrations of prehispanic archaeological materials (lithic and ceramic) on the surface and an area of tombs. In the place anthropomorphic (shamans), zoomorphic, phytomorphic, geometric and abstract representations were found; also, the use of forms in rocks for their stylization. The site in question functioned as a space destined to the development of ceremonial practices and was occupied tentatively between 400 A.C. and 440 AD.
\end{abstract}

Key words: archaeology, ethnography, petroglyphs, grave or burial goods, NicaraguaCaribbean Cost.

Recibido: 16 de marzo del 2019

Aceptado: 24 de mayo del 2019

1 Doctorado en Historia con mención en Estudios Regionales y Locales Trans-Disciplinarios lechadorios@yahoo.com 
En esta investigación son analizados algunos datos obtenidos del estudio desarrollado en el sitio arqueológico "Sombrero Negro", localizado a $250 \mathrm{~km}$ al este de Managua (capital de Nicaragua) y a $6.5 \mathrm{~km}$ al norte del poblado La Batea, en la comarca Sombrero Negro, municipio de Muelle de los Bueyes, en la Región Autónoma de la Costa Caribe Sur (RACCS) de Nicaragua.

El sitio $^{2}$ se caracteriza por la presencia de materiales arqueológicos en superficie, rocas formatizadas, fosas con contenido artefactual y petroglifos elaborados en rocas basálticas, en un territorio geográficamente muy accidentado, con pequeñas lomas y ríos. Las evidencias antes mencionadas son reflejo de las culturas precolombinas que habitaron este territorio y de ellas podemos desprender formas de organización y otras prácticas sociales y económicas. De acuerdo al análisis comparativo de las tecnologías prehispánicas de la región, el sitio fue ocupado tentativamente entre los años 400 a.C y 440 d.C.

Dada la variedad de evidencias arqueológicas identificadas en este territorio, se ha propuesto como objetivo de investigación ampliar conocimientos sobre las prácticas sociales y económicas desarrolladas por el grupo humano que habitó la zona en el período antes referido. Por ello, el presente escrito se enfoca en la identificación y análisis de aquellos elementos ceremoniales presentes en este sitio y el vínculo entre el ser humano y el medio ambiente. La información que se obtendrá de este estudio, se considera novedosa por las particularidades que presentan los elementos constitutivos de este contexto arqueológico, puesto que, hasta la fecha, no se ha documentado en Nicaragua un contexto que reúna las características aquí identificadas, y si lo hay, pues simplemente no se le ha brindado el enfoque requerido.

El auxilio de metodologías y técnicas propias de la ciencia arqueológica, sobre todo, prospección, excavación y análisis de laboratorio, fueron la base de la investigación; haber aplicado la prospección dirigida e intensiva de forma combinada permitió definir la extensión del sitio y conocer la distribución de las evidencias en el espacio.

En la documentación y registro del sitio fueron utilizadas técnicas tales como, uso de calco con papel film, lo cual permite obtener representaciones a escala natural; además, la técnica de relleno de surcos en los petroglifos con papel humedecido, lo que permite resaltar el ancho y forma de los motivos para la documentación fotográfica. Estas técnicas no afectan el estado de conservación de los petroglifos. En el laboratorio del CADI-UNAN, Managua se trabajó con las imágenes a base de programas para dibujo: Ilustrator, Gimp2, photoshop5.0, entro otros.

${ }^{2}$ La documentación inicial del sitio arqueológico Sombrero Negro surge en el marco del proyecto denominado "Fortalecimiento de las Capacidades Turísticas y Mapeo de sitios de cara al Plan de Desarrollo Municipal de Muelle de los Bueyes, RACCS, Nicaragua 2015 - 2016", financiado por el "Programa de fondo de embajadores" de la embajada de Estados Unidos de Norteamérica para Nicaragua y ejecutado por BICUCIDCA con la colaboración científico-técnica del Centro Arqueológico de Documentación e Investigación CADI de la Facultad de Humanidades y Ciencias Jurídicas de la UNAN-MANAGUA. 
Desde el punto de vista geológico, en el territorio se ha observado el predominio de formaciones rocosas basálticas, aunque también se identificó una especie de toba conformada por arcillas con arena endurecida, de color crema y dureza media.

Luego de haber identificado los componentes del sitio, se realizaron pequeñas excavaciones de rescate ${ }^{3}$, por medio de sondeos de control estratigráfico, la fosa principal se extendió $2 \mathrm{~m} \times 1 \mathrm{~m}$ de ancho. Estas acciones se ejecutaron en aquellas áreas donde fue posible observar materialidad expuesta con alteraciones antrópicas significativas. Gracias a ello fue posible identificar tres fosas con depósitos de materiales arqueológicos, debidamente colocados ${ }^{4}$.

Por otra parte, fue necesario auxiliarnos de investigaciones etnográficas y trabajos etnoarqueológicos, entre éstos retomamos los estudios etnográficos realizados en comunidades indígenas bribris de la Costa Caribe Central de Costa Rica (María E. Bozzoli 1976 y 1979 Marta Rizo 2000, Jeffrey Peytrequín Gómez 2011, Patricia Fernández 2013, entre otros). La valiosa información que sobre prácticas sociales y económicas aportaron estos estudios, así como el método retrospectivo usado, nos permitieron hacer las inferencias necesarias para aproximarnos a la comprensión del contexto en estudio y la sociedad que lo produjo.

De momento no se pretende establecer vínculos directos entre las comunidades Bribris de Costa Rica y las comunidades que produjeron el sitio arqueológico Sombrero Negro, pero sí demostrar la importancia que tienen los estudios etnográficos a la hora de realizar interpretaciones sobre los contextos arqueológicos, sean estos regionales o locales, lo cual nos permite obtener una visión más amplia a la hora de querer comprender ciertas prácticas sociales antiguas.

En los próximos párrafos se realiza una caracterización general del sitio en estudio, haciendo mayor énfasis en las evidencias arqueológicas que han permitido definirlo como un contexto ceremonial enfocado en rituales funerarios.

\section{Las Evidencias Arqueológicas}

El área delimitada con presencia de evidencias arqueológicas se extiende en aproximadamente 69.126 ha. Sus límites se definieron en 1,250 m el eje E-O, y 750m en el eje N-S.

\footnotetext{
${ }^{3}$ Se utilizará el término "Excavación de Rescate" para indicar una práctica científica que permite, desde mi punto de vista, estudiar un contexto arqueológico mediante la extracción controlada de cada uno de los elementos que lo constituyen, previamente a su destrucción, ya sea por causa antrópica o natural. Ello permite rescatar la mayor cantidad de información sobre la sociedad que habitó en ese contexto y su relación con el medio. No se enfoca en el objeto como tal, sino en los individuos que participaron en la producción de esos bienes de consumo.

${ }^{4}$ La primera excavación de rescate fue realizada en el 2016, en forma conjunta, por el equipo de arqueólogos del CADI, UNAN, Managua y el BICU-CIDCA. Esta excavación se identificará en este escrito como fosa 1 ó fosa principal. Se denominará fosa 2 y 3 , a los rescates realizados por el personal de la Dirección de Patrimonio Cultural de la Nación (DPCN) en conjunto con el BICU-CIDCA, 2016.
} 
Dentro de esa área fueron identificadas 15 concentraciones de rocas con petroglifos, distribuidas de la siguiente manera: nueve concentraciones en la parte alta de las lomas, donde también se identificaron tres fosas y un área con alta densidad de materiales arqueológico en superficie; las otras seis concentraciones se documentaron a lo largo de un lecho de río llamado Sombrero Negro (CADI, UNAN, Managua. 2016)

El material cerámico recuperado en superficie contiene tiestos pintados en colores rojo y negro, en forma de bandas sobre engobe marrón claro o crema; estas características han sido reportadas en otros sitios arqueológicos del municipio de Kukra Hill y Laguna de Perlas. Por ejemplo, en el sitio Karoline se recuperó cerámica con idénticas características a las del periodo comprendido entre 250-350cal DNE, igualmente, en el sitio arqueológico Cascal de Flor de Pino cuyo periodo va del 800 ANE y el 440 DNE. Importante es que ambos sitios presentan cronologías tempranas asociadas a este tipo de decoración en material cerámica. Richard Magnus, en 1974, agrupa este tipo de cerámicas en lo que denominó Tradición Sitetoide, $400 \mathrm{aC}$ al 1 d.C. Todos los sitios referidos se localizan en el Caribe sur de Nicaragua ${ }^{5}$.

Por otra parte, la industria lítica se caracteriza por artefactos elaborados por medio de percusión directa, sobre todo en sílex y, también, por medio de abrasión en soporte de basalto. Técnicamente fueron identificados núcleos, lascas, láminas y núcleos laminares. De acuerdo a su forma y posible funcionalidad, muchas de esas piezas sirvieron como hachas, puntas de flechas, puntas de lanzas, cuchillos laminares, raederas, machacadores y percutores. Los artefactos macro y micro pulidos fueron elaborados en materia prima de tipo basalto: fragmentos de metates, bastones de mando, fragmentos de manos de metate, fragmentos de pistilos, hachas pulidas y pulidores para cerámica. A groso modo puede decirse que las materias primas son de origen local.

Ha sido posible constatar que en sitios arqueológicos de la RACCS (Cascal de Flor de Pino y Karoline, en el municipio de Kukra Hill) y de la zona Central de Nicaragua (Matiguás), hubo producción intensiva de artefactos líticos tallados por medio de percusión directa con características formo-técnicas similares a los sitios arqueológicos documentados en Muelle de Los Bueyes; esos instrumentos tuvieron función dirigida a raspar carnes, vegetales, inclusive, alisar o depurar la superficie de las cerámicas cuando la pasta aún se encontraba húmeda. (Gutiérrez, M. 2007). Inclusive, en la zona de Brito, Pacífico nicaragüense han sido documentadas industrias líticas similares, lo cual hacer pensar en redes comerciales o de intercambio entre culturas de distintas regiones del país.

El conocimiento en la reproducción de tecnologías cerámicas y líticas, con sus variedades de técnicas, más el uso y estructuración del espacio, son claros indicadores de sociedades

\footnotetext{
${ }^{5}$ Es importante destacar que se ha comparado y triangulado información de las evidencias recuperadas en nuestro sitio de estudio y aquellos contextos que presentan investigaciones sistemáticas y dataciones radiocarbónicas en sitios aledaños. Ello nos permitirá conocer la secuencia cronológica preliminar del sitio en base a la variedad de tecnologías analizadas.
} 
con organización social y económica, muy complejas, donde se pueden determinar saberes ancestrales vinculados con prácticas agrícolas, religiosas, redes de intercambios comerciales entre comunidades localizadas en distintos puntos del territorio nacional y la región centroamericana.

\section{Elementos ceremoniales identificados en el sitio}

Las prácticas ceremoniales son ejemplo claro de una parte de esa complejidad social que se habla en el párrafo anterior, porque cada tipo de ritual (muerte, entierro, danza, matrimonio, enfermedad, etc.) que se lleve dentro de una comunidad contemplará diversas etapas o procesos estructurados para su ejecución, donde deberán existir ciertas condiciones naturales o culturales para que se puedan desarrollar de acuerdo a la idiosincrasia de la sociedad que alberga esa tradición.

Podría decirse entonces, que todo el conjunto de objetos recuperados dentro de las tres fosas identificadas dentro de este sitio, forman parte de esas prácticas ceremoniales con rituales de tipo funerario. Cada fosa se elaboró en un momento único y el contenido de las mismas es irrepetible, porque cada ajuar fue pensado, elaborado y depositado de acuerdo a las cualidades de la persona enterrada.

Se puede observar, además, que en el interior de las fosas existe un idéntico patrón de distribución de artefactos (ajuares), por lo que no cabe duda que el área donde se emplazan estas fosas, corresponde a un espacio sagrado en el cual enterraron personajes de alta jerarquía que, en algún momento de su vida, ejercieron el control o mando sobre la cultura que habitó ese territorio.

Las fosas identificadas en este contexto, contienen objetos con rasgos muy particulares, delicadamente elaborados y decorados, demostrando mucho simbolismo vinculado con el poder de las clases dominantes. Por ejemplo, Úrsula Jones (1992) describe las diversas funciones que ejercieron los metates decorados dentro de las sociedades prehispánicas, atribuyendo usos ceremoniales a todas aquellas piezas con mayor inversión de trabajo en su decoración, proponiendo una secuencia cultural en base de sus rasgos, muchos de los cuales coinciden con los metates recuperado en el sitio Sombrero Negro.

De acuerdo a Patricia Fernández Esquivel (2013) es probable que fuesen incorporados a los contextos como tributo o reconocimiento por su desempeño dentro del grupo o linaje al que perteneció. También se puede pensar que parte de esos objetos se incorporaron como parte de las ofrendas funerarias que acompañarán el alma del deudo en su viaje al más allá, después de la muerte. 
Volviendo al análisis del ajuar recuperado en la fosa principal ${ }^{6}$ (Figura 1), este contenía: tres bastones de mando cilíndricos, de diferentes tamaños, elaborados en basalto y

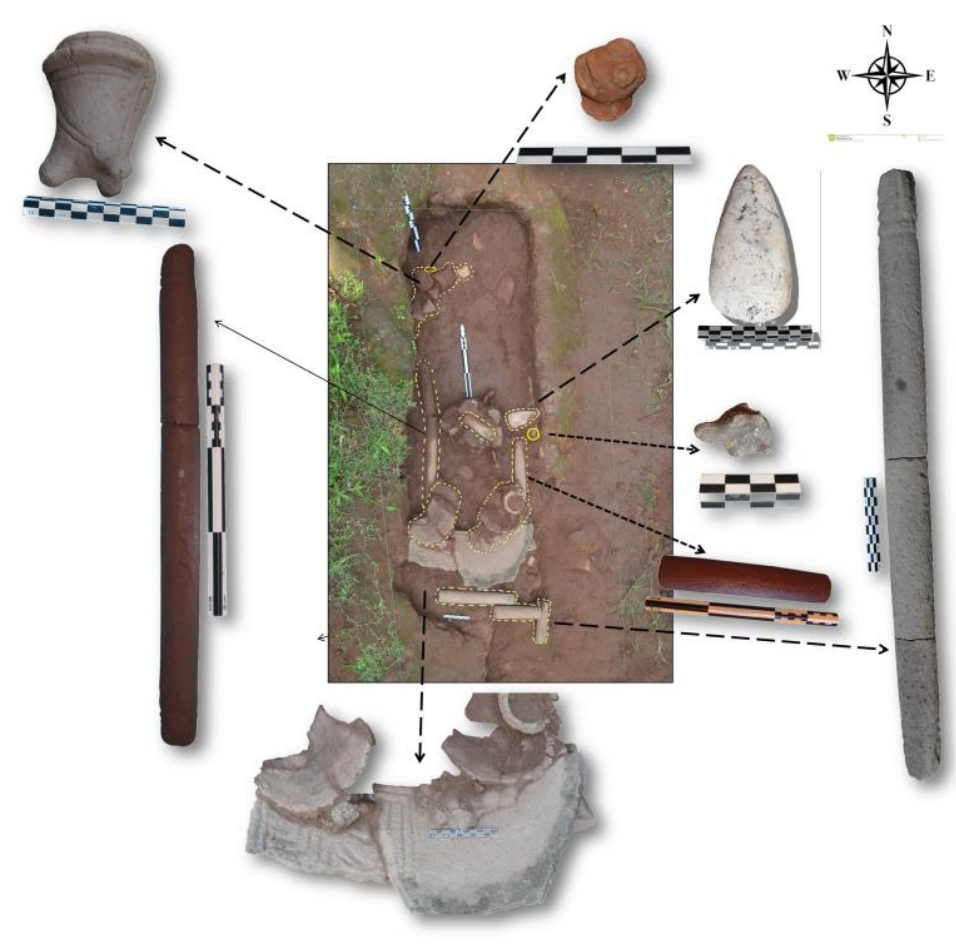

finamente decorados en sus extremos, uno con representación fálica. Dos de esos bastones de mando se encontraban ubicados al centro, y de forma paralela, en los laterales de la fosa, y uno (el que presentaba mayor decoración) se ubicado en el extremo sur de la fosa, de forma perpendicular, asociado al metate. El análisis realizado al depósito artefactual permitió definir que dos de esos bastones fueron fracturados intencionalmente, para posteriormente ser depositado como ofrenda ${ }^{7}$.

Fig. 1. Fosa Principal y su Ajuar Funerario.

Fuente: CADI-UNAN, Managua, BICU-CIDCA, 2016.

El hecho de fracturar intencionalmente los bastones de mando, se puede interpretar como muerte o bien ruptura del ciclo de mando ejercido por el personaje que se estaba enterrando en ese espacio. Patricia Fernández Esquivel (2013: 37-38) refiere que "en la literatura antropológica se conoce como matado ceremonial "o matado de poder" a la actividad de quebrar objetos de forma intencional y ha sido interpretada como acción simbólica que anula la acción de dichos objetos", por tanto, entendible que anula la autoridad que los poseía.

\footnotetext{
${ }^{6}$ Se denominará fosa principal, porque la metodología empleada en su excavación permitió que se documentara la extensión real de la misma; igualmente, porque el tiempo ha facilitado la documentación exhaustiva de los elementos que contenía. Esta fosa se construyó sobre un tipo de toba endurecida tipo cascajo a base de arcilla y arena consolidada, de dureza media. Se orienta conforme los puntos cardinales, con dimensiones de $1.65 \mathrm{~m}$ de largo (N-S) y $0.58 \mathrm{~m}$ de ancho (E-O). El estado de conservación de los materiales en general se define como regular.

${ }^{7}$ Dos de las fosas contienen, por lo menos, un elemento macro-pulido con representación de falo (fosa 1 y 3 ). En una de las fosas no se recuperó bastón de mando.
} 
Yendo hacia el norte del territorio Centroamericano y México, es común ver representaciones de bastones de mando vinculados con el poder en las culturas prehispánicas mesoamericanas, por ejemplo, Manuel Hernann (2007), en el documento titulado "Símbolos de Poder" realiza el análisis e interpretaciones de muchas de las representaciones en códice Mayas y Mixtecas, donde es posible observar bastones de mando como uno de los principales símbolos de las sociedades mesoamericanas.

Sobre los metates documentados, en cada una de las fosas, se pueden apreciar decoraciones finamente elaboradas con representaciones antropo-zoomorfas, reflejando acción ceremonial y posición sedente (Figura 2). En los tres casos, se recuperaron fracturados e incompletos. El hecho de estar fracturados podría perfectamente interpretarse como parte de la acción intencional del ritual funerario y el matado de poder, a como refiere Fernández, pero no se pueden obviar las afectaciones antrópica que sufre el sitio. Es interesante señalar que en ninguno de los metates se logró identificar micro-pulimento por uso, lo que podría dar pistas para pensar en metates elaborados exclusivamente para usos rituales.

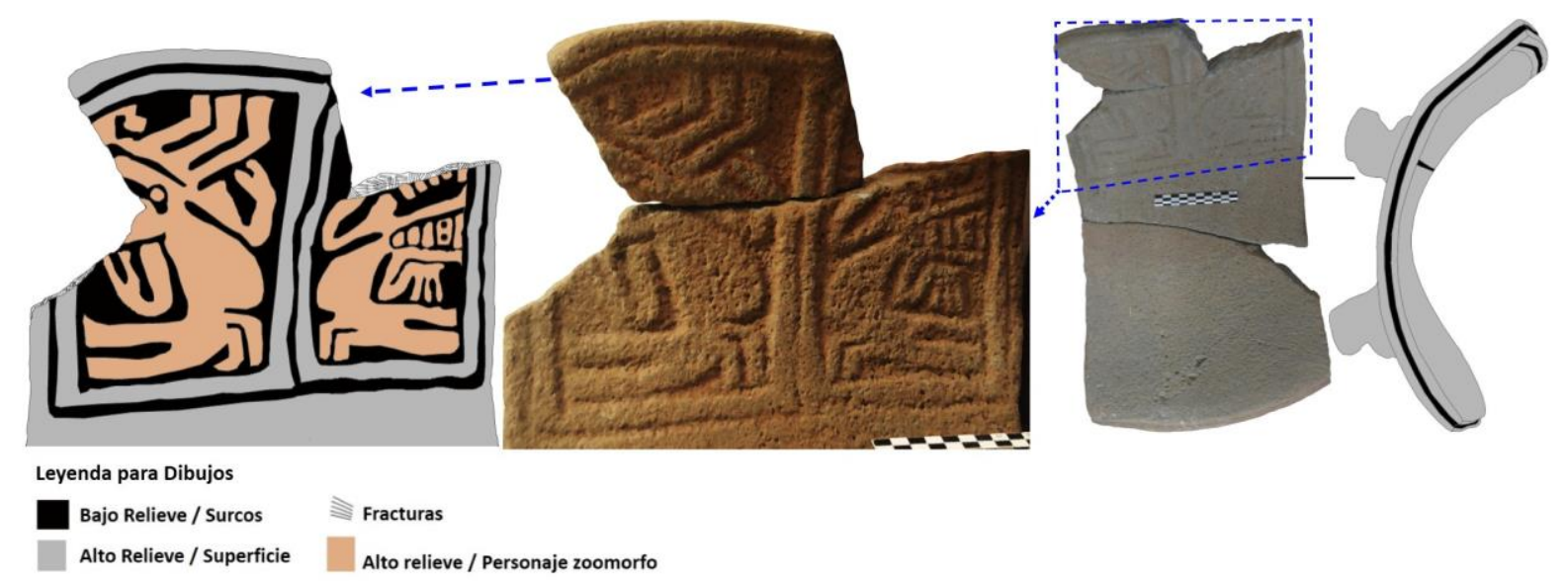

Fig. 2. Metate decorado a doble panel, con personaje zoo-antropomorfo reflejando una actividad ceremonial. Fuente: Leonardo Lechado/CADI, UNAN, Managua, 2017.

Es importante destacar que los metates se localizaban en el extremo sur de las fosas, donde se concentraba la mayoría de objetos, probablemente esta funcionó como cabecera o almohada para el difunto que allí se enterró. Al respecto, Pichardo (2002), en su tesis de licenciatura, analiza y propone diversas funciones para los metates estilizados y decorados recuperados en el área cultural de Gran Nicoya, entre ellas, posibles funciones como asientos o bancos de los caciques o gente de alto rango, también usados como almohadas (Pp.55-57); igualmente, Úrsula Jones (1992) atribuye algunas funciones vinculadas con propósitos especiales (entre ellas ceremoniales). 
En otras zonas del territorio nacional se han documentado prácticas funerarias similares entre las sociedades prehispánicas. Por ejemplo, en el municipio de Ticuantepe ${ }^{8}$, Managua. También en el sitio arqueológico Las Delicias, Managua (ALMA, 2010), se excavó un contexto funerario, donde se documentaron "entierros con ajuares funerarios, entre ellos un metate localizado en el sector de la cabeza, además de dos artefactos líticos, un hacha de basalto grande, un hacha de basalto pequeña" (pág.36). Lo interesante que son sitios distantes, culturas probablemente diferentes y presentan prácticas funerarias similares.

Siguiendo con nuestro caso de estudio, es válido destacar que sobre la superficie de cada uno de los metates documentados, se colocaron pequeñas ollitas globulares, igualmente se colocaron grupos de ollitas más pequeñas en el extremo opuesto a los metates. Complementan el ajuar funerario asas y soportes de barro con representaciones antropomorfas y zoomorfas (entre ellas una figura de perro antiguo ó xulo, una rana y un fragmento de rostro de mujer). Esta figurilla femenina podría estar marcando diferencia de género entre los sepulcros, lo que debería obligarnos a reorientar estudios de futuro en esa línea. Por su parte la presencia de reptiles y símbolos fálicos apuntan a la fertilidad y regeneración (espiritual y del cuerpo).

La fosa principal presenta un hacha micro-pulida elaborada en sílex blanco, es relevante información sobre todo porque la dureza de este tipo materia prima hace que sea difícil su producción por medio de abrasión. Este se localizaba en el lateral derecho de la fosa, asociada a uno de los bastones de mando.

No cabe duda que se trata de un contexto funerario, a pesar de no haber identificado restos óseos: 1-El tamaño de la fosa $(1.65 \mathrm{~m} \times 0.58 \mathrm{~m})$ se ajusta al tamaño promedio de los pueblos originarios centroamericanos, que redondea $1.60 \mathrm{~m}$; 2: la distribución de los objetos en los extremos la fosa, lo que favorece realizar un entierro primario; 3- objetos símbolos de poder, intencionalmente quebrados y depositados indicando muerte o matado de poder.

La ausencia de restos óseos se puede explicar desde los siguientes argumentos:

1- Humedad, composición y acidez del suelo, facilita la degradación del material orgánico, los restos óseos no son la excepción. Se considera que es la explicación más acertada, basados en otras experiencias consultadas sobre contextos funerarios donde se ha presentado este fenómeno, sobre todo en el Caribe, ejemplo: Sitio Cascal de Flor de Pino (KH31) y el sitio Limón, en Corinto, Costa Caribe costarricense.

\footnotetext{
${ }^{8}$ Se hace alusión a esta práctica, en base a los hallazgos realizados en el municipio de Ticuantepe, Managua. En este sitio se realizó el hallazgo de osamentas humanas depositadas sobre metates o piedras de moler. Según la arqueóloga María Lily Calero, (END, Sábado 25 y martes 28 de Junio 2016) "Es un individuo adulto, enterrado sobre unos metates (piedras de moler); y dos ofrendas, con restos óseos dentro, que son las urnas" $\mathrm{y}$ "... nosotros pensamos que debe tratarse de un individuo importante".
} 
2- Cabe la posibilidad que los restos óseos hayan sido depositados en la fosa, en forma de cenizas dentro de las ollitas, podríamos relacionarlo con las ollitas que se recuperaron sobre los metates, sin embargo, harían falta estudios para fortalecer esta hipótesis.

A diferencia del sitio Sombrero Negro, en el sitio arqueológico Monkey Point (un montículo creado a base de acumulaciones de conchas, comúnmente llamado conchero), localizado en el litoral caribeño al sur de Bluefields, se descubrió una osamenta humana de mujer adulta, depositada en posición decúbito dorsal con las extremidades inferiores flexionadas y las extremidades superiores extendidas. No presentaba ajuar alguno asociado, únicamente pequeños clastos basálticos planos que fueron depositados como base del entierro. Las fechas radio-carbónicas datan al sitio entre $6140 \pm 30$ BP (Balladares, S. Gaitán, G. y Lechado, L. 2014; Byers, D, et. al. 2014). Lo interesante de esto es que a pesar de ser la evidencia física humana más antigua del territorio nacional ${ }^{9}$, también es la primera documentada en concheros del Caribe nicaragüense y probablemente centroamericano, su conservación se vio favorecida por el hecho de haber sido depositada en una matriz conchas y desechos quemados que permitieron su calcificación.

$\mathrm{Si}$ a la evidencias material recuperadas en este espacio, le sumamos las diversas representaciones identificadas en los petroglifos que conforman el sitio (chamanes, danzantes, antro-zoomorfos) fortaleceríamos la noción que en este espacio se practicaban actividades ceremoniales enfocadas al sepulcro de personajes de alta jerarquía, en época temprana. Estudios etnográficos realizados por Maria Eugenia Bozzoli reflejan que la muerte de un líder o jefe de la comunidad, es también causa de alegría por la transición del alma a un plano superior (1977) y ello implica prolongadas ceremonias (danzas, comidas y bebidas).

\section{Chamanes y Danzantes}

La variabilidad de motivos documentados en este sitio, deja entrever una cultura que quería plasmar diversos aspectos de la naturaleza, prácticas sociales y la relación del ser humano con la naturaleza en un espacio muy particular. Es difícil saber, a ciencia cierta, lo que pensaban las personas que elaboraron esos petroglifos, sin embargo, ha sido posible aproximarnos mediante el análisis detallado de los componentes del sitio.

\footnotetext{
${ }^{9}$ De acuerdo a la comunicación personal de la Doctora Lourdes Domínguez, "el sitio arqueológico Monkey Point es tomado como referencia en Cuba al abordar el poblamiento temprano del Caribe Insular", igualmente para el estudio del Meso-Caribe o Mediterráneo Americano, términos valorados y discutidos en el seno del curso "Pueblos Originarios y Formación Regional en América Latina y el Caribe".
} 
En el análisis general de los petroglifos, se pueden identificar elementos de la naturaleza que en su momento existió. Se han podido identificar petroglifos con representaciones antropomorfas (caras, cuerpos, extremidades), zoomorfas (ave, felino, mono, perro, monos, guardatinajas, peces, reptiles, arácnidos, serpientes, tortugas, cocodrilos y ranas), fitomorfas

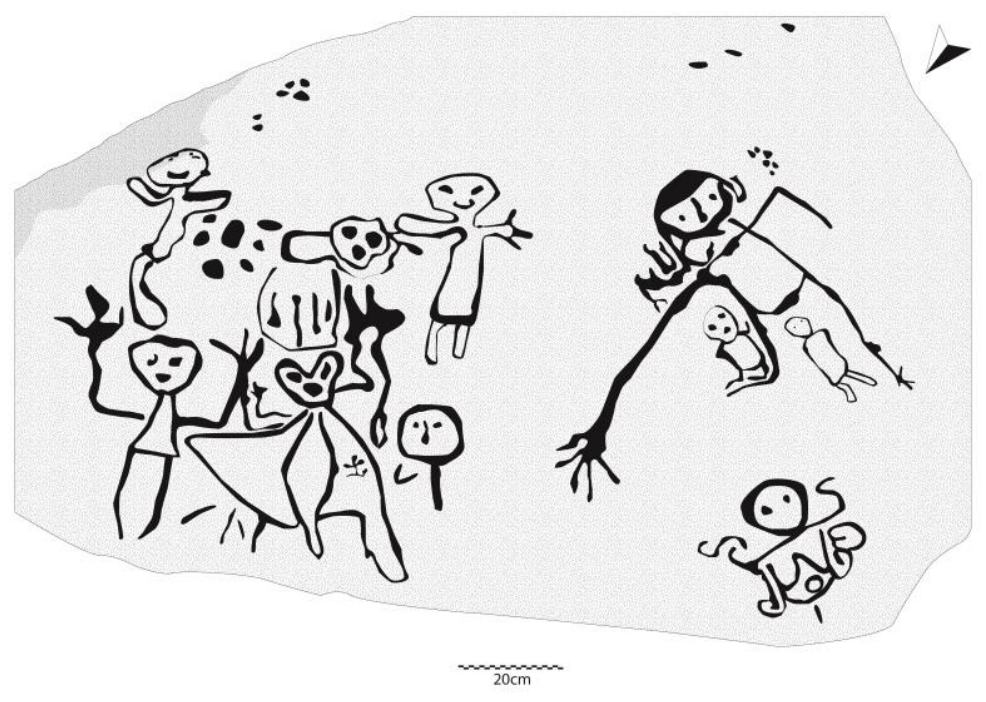

(flores, árbol cósmico o de la vida), geométricas (líneas, círculos, cuadros, espirales, puntos, rectángulos) y abstractas. En ocasiones se aprovecharon las formas de las rocas para su estilización tridimensional, logrando en algunos casos, representaciones de animales (cocodrilos y ave). Se identificó una sola figura bicéfala con cabeza en cada uno de sus extremos.

Fig. 3. Roca con grupos danzante.

Fuente: CADI-UNAN, Managua, BICU-CIDCA. 2016

Las representaciones de caritas igualmente se han localizado en todo el sitio, dispersas y en agrupaciones. Reflejan diversos estados de ánimo (alegría, tristeza, asombro) y gestos (danzando, agarrados de la mano como en ceremonia, sentados, alzando las manos), en fin estados de ánimos que perfectamente se pueden asociar con fases de ciertas prácticas ceremoniales.

Entre las figuras antropomorfas y zoomorfas se puede apreciar lo cóncavo y convexo, como complemento perfecto en la cosmovisión de esta cultura, destacan personajes danzando, en ocasiones una sola figura y en otras, grupos bailando colectivamente. Se identifican conjuntos de motivos con grupos familiares danzando. Esto se observó claramente en una roca localizada próxima al área de entierros, la cual presenta tres conjuntos antropomorfos danzando, cada uno con tres miembros, donde se pueden observar adultos (hombre y mujer) e infantes (Figura 3). Cabe mencionar que dependiendo de la inclinación de los rayos del sol, la postura de los danzantes varía, lo que nos permite inferir sobre los tipos de movimiento realizados a la hora de danzar. 


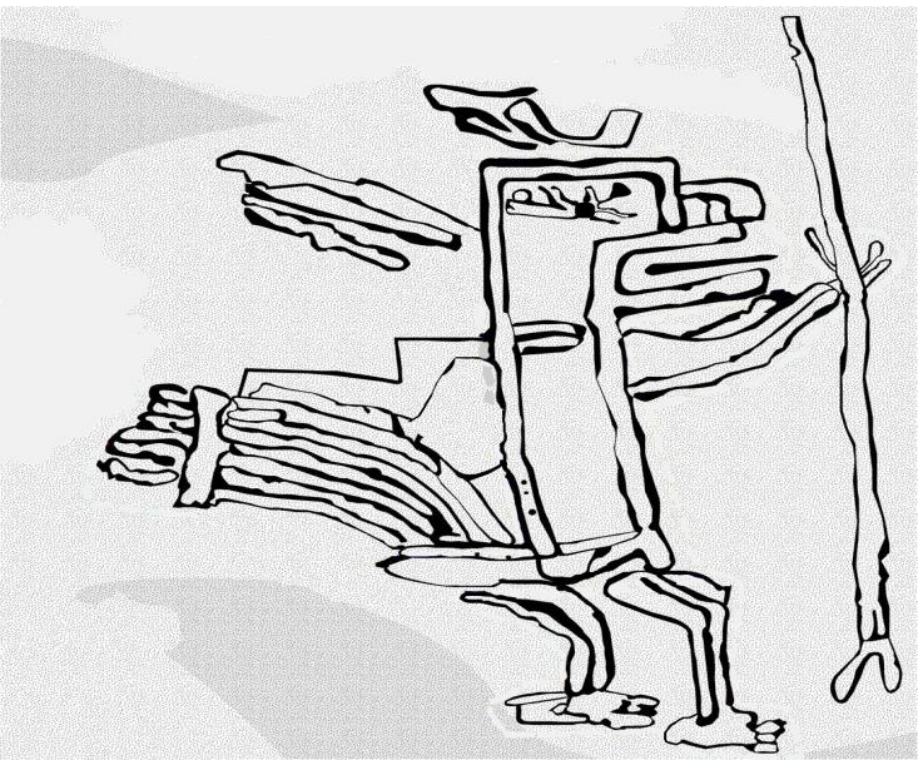

Fig.4. Representación de Chaman con bastón de mando. Fuente: CADI-UNAN, Managua, BICU-CIDCA, 2016.
Por otra parte, ha merecido particular atención la representación de un personaje que seguramente ejerció algún tipo de poder dentro de esta cultura, quizá un posible chamán (Figura 4). Es una figura antropozoomorfa muy estilizada sosteniendo con sus dos manos un "bastón de mando". Podría valorarse, esta imagen, como el elemento que hace alusión directa al espacio sepulcral, un espacio de élite, donde se enterraban chamanes $\mathrm{o}$ personajes de liderazgo dentro de la comunidad.

Al respecto, Manuel Hernann (2007), realiza el análisis e interpretación de cetros o bastones de mando a partir de los códices Mayas y Mixtecas, como uno de los principales símbolos de las sociedades mesoamericanas. Expresa lo siguiente:

"Tanto en Mesoamérica como en otras partes del mundo uno de los principales atributos del gobernante es representado por el cetro, pues a nivel universal el cetro simboliza el eje del mundo y el centro del cosmos; de tal modo, el soberano que lo porta se constituye a sí mismo como eje rector de ese universo. Según nos dice Mercedes de la Garza: "el cetro es a nivel universal, un modelo reducido del bastón de mando, símbolo vertical que representa primero y después al hombre poderoso y el poder recibido de los dioses". (Pág 80).

El trabajo invertido en la figura descrita con anterioridad, refleja diversos elementos de la naturaleza (pies y brazos humanos, cola y tocado aviforme, fauces de felino, bastón de mando, cola de cocodrilo, entro otras). Se valora como una representación de poder con dominio sobre 3 de los 4 elementos de la naturaleza: aire (reflejado por medio del ave), agua (el reptil) y tierra (el ser humano). La dualidad y concepción de la transformación del ser humano en animal está claramente reflejado en este personaje que sin duda alguna ser alguien de mucha importancia dentro de esta sociedad.

No se puede dejar de mencionar el conocimiento astronómico que poseía esta cultura, y en particular el chamán o líder de la comunidad, sobre el movimiento de los principales astros (la luna, el sol y los ciclos), diversos petroglifos identificados en este espacio se vinculan con adoración a estos astros. 


\section{Consideraciones finales}

Como se puede notar, los elementos de la naturaleza fueron profundamente valorados dentro del desarrollo de estos pueblos, no solo para suplir necesidades materiales y alimenticias, sino también, necesidades espirituales en armonía con el medio ambiente.

No pretendemos que nuestras interpretaciones sean consideradas como absolutas, por el contrario, perseguimos generar ejes temáticos de discusión que deberían abordarse en análisis de contextos arqueológicos similares al sitio Sombrero Negro. Por lo menos en la literatura arqueológica nicaragüense, muy poco se profundiza en el análisis de estos tipos de contextos ceremoniales, comúnmente, las interpretaciones suelen ser muy simplistas o bien descripciones de los motivos identificados, pero es necesario ir más allá de eso.

Es muy difícil establecer una adscripción crono-cultural precisa en esta fase de los estudios, debido a que se están encontrando elementos iconográficos muy tardíos y característicos de culturas mesoamericanas (serpientes, cocodrilos, chamanes); pero también, se identifican elementos líticos (metates) muy estilizados vinculados con el área sur de Centroamérica (área chibchense), inclusive el material cerámico diagnóstico refleja periodos tempranos entorno al inicio de nuestra era, lo que ha permitido ubicar tentativamente el sitio entre $400 \mathrm{aC}$ y $440 \mathrm{dC}$.

Se ha podido determinar que los petroglifos localizados en el río fueron elaborados cuando el río mantuvo bajo niveles, probablemente entre los meses de diciembre a mayo cuando el promedio de lluvia en el Caribe nicaragüense disminuye; por el contrario, las evidencias de las partes altas de los lomas, y sobre todo el área con las fosas, reflejan condiciones para uso del espacio en cualquier época del año, lo que probablemente sugiere que las actividades se alternaban de acuerdo a la época del año.

Muchas son las lecturas que se pueden realizar sobre un sitio con las características de sombrero Negro, porque los petroglifos son el único documento escrito encontrado y nadie sabe lo que el autor pensaba al momento de realizarlos, pero gracias al análisis de la materialidad asociada se ha podido ir complementando la lectura de este contexto y aproximarnos al conocimiento sobre su funcionalidad. Aunque es válido señalar que el enfoque de la investigación, va dirigido al análisis de los elementos que se consideraron ceremoniales y rituales, es importante destacar que hace falta profundizar en otra serie de aspectos sociales y económicos que propiciaron el desarrollo de estos pueblos.

Comprender el poblamiento antiguo de la Costa Caribe nicaragüense no es tarea fácil, pero, es satisfactorio poder aportar nuevos datos contribuyan al conocimiento de algunas de las prácticas sociales y económicas de las culturas que habitaron este territorio. Queda mucho camino por recorrer para armar este complejo rompecabezas histórico, lo importante es no claudicar en este sentido. 


\section{AGRADECIMIENTO}

Llegado a este punto, es importante resaltar el apoyo que me brindó la UNAN, Managua, por medio de los Fondos para Proyectos de Investigación (FPI), los cuales facilitaron mi movilidad y estadía, por una semana, en la ciudad de Bluefields. Ello permitió desarrollar el análisis de la colección arqueológica del BICU-CIDCA.

Igualmente eso destacar la valiosa colaboración que brindó el señor Donald Byers, director del BICU- CIDCA de Bluefields, quién facilitó el acceso a la materialidad arqueológica que resguarda este centro y a los informes técnicos que existen sobre el sitio en estudio. Igualmente, se agradece al arqueólogo del proyecto Bani Barberena, quién colaboró en labores de tratamiento y análisis de los materiales y las colecciones arqueológicas existen. Los análisis realizados a esa materialidad complementaron y fortalecieron las interpretaciones previas que sobre el sitio se habían presentado en los informes precedentes.

\section{REFERENCIAS BIBLIOGRÁFICAS}

ALMA. (2010). "Las Delicias: poblado indígena más antigua de Managua". Revista Nuestra identidad. Año 1, número 5. Dirección de cultura y Patrimonio Histórico municipal. Alcaldía de Managua, Nicaragua.

Balladares, S., Gaitán, G., y Lechado, L. (2014). "Resultados de dataciones radiocarbónicas del sitio arqueológico Angi". Humanismo y cambio social. (3). Pp.132-134.

Bozzoli, M. E. (1979). El Nacimiento y La Muerte entre los Bribris. Editorial Universidad de Costa Rica, Costa Rica.

Bozzoli, M. E. (1976). "La esposa del Bribri es la hermana de Dios". América Indígena. Vol. XXXVI, no. 1, enero-marzo. San José Costa Rica.

Byers, D; Balladares, S; Gaitán, G; Serano, J; Lechado, L. 2014. "Patrimonio Cultural y Arqueológico del Territorio Rama y Kriol. Verificación e Inventario". WANI, Revista del Caribe Nicaragüense. $\mathrm{N}^{\mathrm{o}} 70$.

CADI-UNAN, Managua. (2011). Visita al sitio arqueológico Cara de Mono. Un centro ceremonial del pasado. Informe técnico. Inédito. CADI-UNAN-Managua. Nicaragua.

CADI-UNAN, Managua. (2016). "Documentación Arqueológica del Sitio Sombrero Negro, municipio de Muelle de los Bueyes, RACCS”. Informe Técnico. Inédito.

Clemente C, I. y Gassiot Balbé, E. (2004/5). “¿En el camino de la desigualdad? El litoral de la costa caribe de Nicaragua entre el 500calANE y el 450 calNE". Revista AtlánticaMediterránea de Prehistoria y Arqueología Social (RAMPAS) vol. 7, pp. 109-130.

END. (2016, junio 28). "Nuevos hallazgos arqueológicos en Ticuantepe". El nuevo Diario. Managua, Nicaragua.

END. (2016, junio 25). "Impresionante hallazgo de piezas arqueológicas y zona funeraria en Ticuantepe". El Nuevo Diario. Managua, Nicaragua.

Fernández Esquivel, P. (2013). Entre Entierros y Rituales: Los Jarrónes Trípodes Del Caribe Central de Costa Rica $(300 \mathrm{aC}-800 \mathrm{dC})$. 1a ed. Fundación Museos del Banco Central. San José, Costa Rica 
Gaitán Solano, G. (2012). "La Gestión del patrimonio arqueológico. Sitio Cara de Mono en el municipio Muelle de los Bueyes, RAAS". Tesis de licenciatura. Inédito. CADIUNAN-Managua. Nicaragua.

Gorín, F. (1990). “Archeologie de Chontales, Nicaragua”. La Ceramique. Tomo II Cap VII. Pp.260-488.

Gutiérrez, M. (2007). “Análisis de la industria lítica del sitio arqueológico Karoline (KH4). Tesis de Licenciatura. Inédita. CADI, UNAN - Managua. Nicaragua.

Hermann Lejarazu, M. (2007). "Símbolos de poder: un análisis comparativo entre la iconografía del clásico maya y los códices mixtecos". Revista Estudios de Cultura Maya. Vol. XXX. Pp.79-106. México.

Jones, U. 1992. Decorated Metates in Prehispanic Lower Central América. Vol I y II. University College, Londres, Inglaterra.

Kunne, M. y Strecker, M. (2008), "Arte rupestre de México oriental y Centroamérica". WANI. Vol 57. Pp. 60-78. Bluefields, Nicaragua.

Magnus, R. (1974). The Prehistory of the Miskito Coast of Nicaragua: A Study in Cultural Relationships (Tesis Doctoral). Yale University, Estados Unidos de Norte América.

Oporta Fonseca, D. (2013). "Huellas ancestrales de Piedras Pintadas: Una estrategia de gestión cultural en Villa Sandino-Chontales". Revista Universidad y Ciencia, UNANManagua, Vol. 7, $\mathrm{N}^{\circ}$ 11. S/p. Managua, Nicaragua.

Peytrequín Gómez, J. (2011). "Identidad y prácticas rituales funerarias en Costa Rica, 300800 d.C. Una interpretación". Cuadernos intercambio sobre Centroamérica y el Caribe. Año 8, n. 9 . Pp. 249-270. San José Costa Rica.

Pichardo, L. (2002). Metates: Evidencias de poder de la Nicaragua Precolombina. Tesis de Licenciatura. Inédito. CADI-UNAN-Managua.

Rizo Vivas, M. (2000). La maternidad de la mujer Bribri: un análisis desde la metodología etnopsicoanalítica. Tesis de licenciatura. inédita. UCR, San José, Costa Rica. 